\title{
GETTING IN AND STAYING THERE; CHILDREN WITH DOWN SYNDROME IN MAINSTREAM SCHOOLS
}

\author{
Pat Cuckle \\ School of Education, University of Leeds, UK.
}

\begin{abstract}
The proportion of children with Down syndrome in mainstream schools, compared to special schools, has been increasing over the last decade; this is due both to more children going into mainstream schools at five or six and to more children staying in mainstream schools for increasing lengths of time, not uncommonly throughout their school careers. There are, however, wide variations between Local Education Authorities, which is attributed mainly to differing implementation of inclusion policies. Data is drawn together from a number of sources (both previously published and unpublished) which describe some of the processes which take place in making initial placements in mainstream schools, maintaining those placements and transferring out of mainstream schools. Commitment of staff to meeting children's special needs rather than matters relating to the curriculum seem to be of paramount importance both at home and abroad in successful mainstream placements.
\end{abstract}

Keywords - Down syndrome, mainstream school, placement, factors

\section{Introduction}

The Education Acts of 1981 and 1993 have brought about a great change in including children with all levels of learning difficulties in mainstream schools. Inclusion of children with statements in mainstream schools has increased and has been noted by Norwich (1994; 1997). This trend is reflected for children with Down syndrome (DS), most of whom will have a range of special educational needs (SEN) and learning difficulties and most of whom will have a statement. This article discusses factors involved for children entering mainstream schools and continuing there. It draws together information from a number of published studies, as well as previously unpublished data; one set of data from parents in the early 1990s relates to processes involved in school placements, and the other relates to data from Local Education Authorities (LEAs) on inclusion policies collected in 1998.

\section{Acquiring a place in mainstream school}

A study of over 3,000 children aged five to sixteen with Down syndrome in England and Wales showed an increase in the proportions in mainstream schools from about $4 \%$ to $38 \%$ in the years between 1983 and 1996 (Cuckle, 1997). There are two reasons for this increase; more have gone into primary school at five or six years old in recent years and more have stayed in mainstream than previously. One of the most important 
factors to emerge from this study was the great variation in mainstream placements across the country, dramatically so for those starting school at five and six; the top quarter of LEAs had $67 \%$ or more in mainstream while the lowest quarter had 28\% of less. Norwich (1994; 1997) demonstrated similar local variations for all children with statements of SEN. There was a strong correlation between Norwich's (1997) LEA data and data on children with Down syndrome (Cuckle, 1997); where LEAs had high proportions of all statemented children in mainstream schools, they were also likely to mainstream high proportions of children with DS. As expected, in each LEA the proportions of children with DS in mainstream were smaller than all children with statements. Booth (1996) showed that for secondary school age children with DS in eight LEAs the percentage in mainstream varied between $2.5 \%$ and $50 \%$.

In order to explain the local differences found in Cuckle (1997) and in Norwich (1994; 1997) 12 LEAs with widely varying proportions of children with DS in mainstream schools were contacted by telephone. Officers responsible for placements were asked about their LEA's policies and what role the parents had in initial placements. Without exception, officers indicated that they had for some time worked towards mainstreaming children and maintaining placements wherever possible; they also indicated that they were working towards more inclusion in the light of recent recommendations (DfEE, 1997). This was reflected in written policies which were made available for examination. Since there is no reason to suppose that one group of children is any different from a group in a neighbouring LEA, it would seem that LEAs have different ways of interpreting and implementing policies for school placements, particularly the proviso "wherever possible".

Judgements may be made about ability in placing a child or there may be special school places to fill if a judgement has been made that resources are best used by concentrating them in special schools. Booth (1996) said that there was no single perspective on inclusion over a number of authorities, there was great variation and there were arbitrary decisions about whether similarly able children with Down syndrome were on the roll of a special or a mainstream department of a "devolved special school" depending on the route they have taken through the system. Goodey (1996) suggested that some LEAs have proportionately more places to fill in special schools than other LEAs and a mainstream placement may depend on how much the parents protest. Parents can often find great support from parents' groups in their area. Support groups can be very empowering; a local group may know which schools are willing to take children, know how to avoid or resist any difficulties they meet and can lend moral support to parents who feel they have a difficult task ahead of them.

Much depends on LEA policy; the same child would be in a mainstream school in, for example, Newham, a highly inclusive borough, (Jordan and Goodey, 1996) but if s/he moved to another part of the country, would be likely to be in a special school. In the Netherlands (Scheepstra et al, 1996) the number of children with Down syndrome in "regular education" has been growing, and the authors attribute considerable influence to parental support groups in encouraging parents to seek mainstream placements; this was also suggested in Cuckle (1997). Some earlier work had been carried out involving a series of 13 case studies of children aged between three and twelve in the early 1990s. The study investigated reasons for choosing a particular type of school, parental satisfaction with the school attended and the reasons for children transferring to another type of school. Two of the children were pre-school age, and the parents wanted mainstream places, one at a denominational school outside the borough. Of the 11 children of school age, one had always been in special school; his parents thought that given his severe level of learning difficulty combined with other physical problems, the school was the best choice and were content with his schooling, particularly activities such as riding and swimming which were on offer. The remaining 10 of the 11 had started off in mainstream schools and the main reasons for that choice were that parents thought their language and social skills would benefit if they were with "ordinary" children similar to parents in Scheepstra et al (1996). Five of the 10 had gone to the same school as their 
siblings, but of the other five all parents reported that they had had to look around a number of schools to find one which would accept their children. This was again similar to Scheepstra et al (1996) who found that it was usually the parents' responsibility to find a school willing to accept their children; parents with children in "regular" schools were generally more educated than the average and presumably more able to make a cogent argument for "regular education". Since the early 1990s the situation for finding a school seems to have changed; when asked about the process of making placements in a mainstream school, LEA officers (as described earlier) generally said that they would be driven by parents' preferences and that most children would go to their local school after liaising with the school and the LEA officer. Some schools had built up considerable expertise with children with Down syndrome and if a place was requested outside the local school, officers would usually liaise and try to meet the parents' requests. Most children would start off in mainstream nursery classes with the intention that everyone would "see how it goes"; with regular reviews the hope would be to maintain a mainstream place as long as possible. However, in one area, many children attended a special nursery from the age of two before moving to mainstream nursery and reception classes at four having been well prepared to cope. In another LEA the officer said that in the last year or two there had been a number of requests for special school placements since parents thought that more money and therefore better resources would be available, although this was not in line with the LEA's developing inclusion policy. Some LEA officers made the point that willingness and commitment on the part of the school to accept a child was very important to the success of a placement. This is reiterated in Scheepstra et al (1996) whose parents usually entered into a dialogue with the schools over expectations at the time of placement; the decision to accept the child generally was made by the staff as a whole.

\section{Maintaining a place in mainstream school}

Factors which influence obtaining a mainstream placement include in which LEA a child lives and how that LEA interprets and implements its policy inclusion policy. Having been placed in a mainstream school, what influences whether an individual child stays there? From about 1,000 complete school histories, Cuckle (1997) saw that in recent years more children with DS had stayed in mainstream schools than previously, however children did still transfer to special schools most typically around age 9 and again at eleven or twelve. The study did not address the question of what contributes to continuing mainstream placements, however there are a few small studies which contribute some information.

In the early days of mainstream placements, Budgell (1986) found that although there were a number of children who started in mainstream in one particular LEA, there was only one who continued to secondary school. He suggested that younger children were more easily accommodated in a "child centred" infant classroom than in a more formal, academically orientated class at an older age. It may be that Key Stage 1 makes different demands of the child than did infant classes of the eighties, however the "child centredness" of the KSI classrooms is likely still to be an important factor. From the case studies of 13 children in the early nineties described earlier, the main reasons parents gave for children transferring from mainstream to special schools were connected with increasing falling behind in academic progress; both parents and teachers had felt that the it was becoming more difficult to meet their needs (both academic and social) in an increasingly "academic" atmosphere. Three of the parents spoke of considerable pressure to transfer their children to special schools, for example one child was excluded from school whenever his support staff was unavailable through sickness or training; the school feared that if the LEA knew they could accommodate the child without support staff, then the support will be cut back or withdrawn. The parents found this kind of periodic exclusion intolerable, and interpreted it as harassment and insufficient commitment to meeting his needs. Other parents commented that their children had been placed in mainstream schools, but without a real commitment on the part of the school to accommodate their needs. They commented that it seemed more a case that 
the child has been granted a place and so must prove to be worthy of it. Children were often placed with a younger year group and this may have been appropriate at five or six, but not appropriate later on as children stayed two or more years behind, usually loosing friends who moved on. Especially if the parents believed their children were not really gaining anything from being kept behind, this was sufficiently frustrating for parents to feel pressured into transferring children to special schools. However, three of the children were in a LEA who had closed their moderate learning difficulties (MLD) special school places and these three then had to transfer to a special school in a neighbouring LEA. Staff in the new school perceived and resented the situation as one of having "to pick up the pieces of a failed mainstream placement from another LEA"; not a conducive atmosphere for the child to enter.

There is, of course, a more positive side to transfer. When some children enter mainstream school the expectation of both parents and teachers is that they will stay there as long as possible, gaining a good basic academic and social grounding but by 9 or 10 it will be more appropriate to transfer to special school where they will gain from more specialised teaching and facilities. Amongst parents who felt positive about transfers to special schools (from the 13 case studies above), the facilities they liked were a higher ratio of staff to pupils, more cooking and practical skills, teaching of life skills and preparation for work, more access to swimming and speech therapy and well organised out of school activities such as brownies, cubs and drama and dance groups which were organised in the school at a suitable pace for the children.

There are cases where children transfer from special school to mainstream school later in their school career. When families move to a new geographical area they may have this opportunity, usually in cases where the new LEA has a higher proportion in and greater commitment to inclusive education. Families sometimes are able to move to and deliberately choose a LEA where they know their child can attend a mainstream school. In one LEA one of the special schools caters only for children up to 11 , and many then transfer to a specially resourced high school rather than to another special school (Cunningham et al, 1998).

If commitment on the part of a school and its staff is important in acquiring a mainstream place, it seems it is crucial to maintaining a place through primary and into secondary school. Two children from the sample of thirteen (described earlier) had remained in mainstream schools (at the time of the study they were nine and ten) and what was striking about the parents' descriptions of school life was how they conveyed a sense of commitment on the part of the school. One was a grant-maintained denominational school with a policy for integrating all types of special needs, the other was a school whose entire staff involved themselves in welcoming and integrating the child; they publicly celebrated this boy's achievements, for example the camping and first aid skills he gained at Scouts and his abilities in dance and drama. There are a multitude of individual accounts of successful placements reported via the periodic magazine for parents produced by the national Down Syndrome Association. What schools which provide continuing, successful placements have in common is a strong commitment to catering for the children's all round development; academic achievements may not have always be a priority, although there have been recent reports of young people gaining very impressive passes at GCSE level and going on to higher qualifications sometimes in school but more often in Further Education colleges.

In the Netherlands (Scheepstra, 1996) the parents and school staff usually discuss and agree on conditions to be met for maintaining a place. Conditions included the school's belief that it has something to offer the child, evidence of the child's continuing happiness and progress and the teacher having sufficient time to devote to the rest of the class.

The quality of support available to children (and normally supplied as part of the statement of SEN) is likely to affect the success of a placement. In a highly integrating LEA a fundamental change in support at 8 years old from trained nursery nurses to untrained classroom assistants affected 
schools' perceptions of ability to cope, with consequent transfer to special schools (Lorenz, 1995). Levels of skill and training vary widely; some children will have a well-trained nursery nurse while others will have a support person with no special qualifications although training may have been planned for some future date. Special needs assistants are increasingly receiving training and there are now specialist publications for them to use (e.g. Lorenz, 1998). It is important that the curriculum is thoughtfully differentiated for children with DS, particularly in the area of language with which most children will experience difficulties (Alton, 1998).

Booth (1996) found, in a small number of case studies, that a child's performance (and most likely consequent decisions about maintaining a placement) depended very much on the quality of interaction with individual teachers in individual lessons. Interestingly, Scheepstra et al (1996) found that their sample were more likely to be in the classes of older and, therefore, more experienced teachers. Social as well as academic factors are clearly important to parents in preferring a mainstream placement and social disharmony was an important aspect in deciding to transfer. Sherman (1995) commented that social inclusion takes effort (either subtle or overt) on the part of the teachers, assistants or carers; it does not usually occur spontaneously. It can be very easy to look for and find reasons to reject a special child from a mainstream school. To help make a placement successful, it usually takes considerable resourcefulness in terms of underlying attitudes within a school, commitment to staff training and willingness to have realistic expectations about what the child can achieve. It makes all the difference if a child is seen as having special needs to be met rather than a problem to be overcome.

\section{Correspondence}

Dr Pat Cuckle, School of Education, University of Leeds, Leeds, LS2 9JT, UK.

Telephone +44(0)1132334581

E-mail_p.m.cuckle@education.leeds.ac.uk

\section{References}

Alton, S. (1998). Differentiation not discrimination: developing the curriculum for children with Down syndrome in mainstream schools. Support for Learning. Vol. 13 (4) pp 167-173.

Booth, T. (1996). A perspective on inclusion from England. Cambridge Journal of Education. Vol. 26 (1), pp 87-99.

Budgell, P. (1986). Drifting towards segregation. British Journal of Special Education. Vol. 58 (3), pp 279286.

Cuckle, P. (1997). The school placement of pupils with Down syndrome in England and Wales. British Journal of Special Education. Vol. 24 (4), pp 175179.

Cunningham, C.C., Glen, S., Lorenz, S., Cuckle, P. and Shepperdson, B. (1998). Trends and outcomes in educational placements for children with Down syndrome. European Journal of Special Needs Education. Vol. 13 (3), pp 225-237.

DfEE (1997). Excellence for all children. Meeting Special Educational Needs. HMSO, London: UK.

Goodey, C. (1996). Vested interests. Special Children. Vol 90 (February), pp 17-19.

Jordan, L. and Goodey, C. (1996). Human rights and school change: the Newham story. CSIE: Bristol: UK

Lorenz, S. (1995). The placement of pupils with Down syndrome: a survey of one northern LEA. British Journal of Special Education. Vol 22 (1), pp 16-19.

Lorenz, S. (1998). Children with Down syndrome: A guide for teachers and learning support assistants in mainstream primary and secondary schools. David Fulton Publishers, London: UK.

Norwich, B. (1994). Segregation and Inclusion (English LEA Statistics for 1988-92). Centre for Studies in Inclusive Education: Bristol, UK.

Norwich, B. (1997). A trend towards inclusion: statistics on special school placements and pupils with statements in ordinary schools, England 199296. CSIE, Bristol: UK

Scheepstra, A.J.M., Pijl, S.J. and Nakken, H. (1996) "Knocking on the school door"; pupils in the Netherlands with Down syndrome enter regular education. British Journal of Special Education. Vol. 23 (1), pp 134-138.

Sherman, Ann. (1995) I hardly feel like I am playing; differing intentions with regards to social inclusion. Early Years. Vol. 16 (1) pp 51-54. 